\title{
Investigation of the Permeability of Pure Gases in Sol-gel Derived
}

\section{$\mathrm{Al}_{2} \mathrm{O}_{3}$ Membrane}

\author{
B. Topuz, M.Çiftçioğlu and F. Özkan
}

Materials Science and Engineering Program , İzmir Institute of Technology, Gülbahçe URLA, IZMiR

Key words: Sol-gel, membrane, ceramic, alumina, gas permeation

\begin{abstract}
The preparation, characterization and pure gas permeation of sol-gel derived alumina membranes were investigated in this work. The effects of acid concentration/type and water content on the particle size in the sols and pore size distributions of the unsupported membrane were investigated by $\mathrm{N}_{2}$ adsorption/desorption isotherms and Dynamic Light Scattering. Increasing the $\mathrm{H}^{+} / \mathrm{Al}^{3+}$ mole ratio from 0.1 to 0.25 caused the hydrodynamic sol particle size and BJH pore size to decrease from 65 to $30 \mathrm{~nm}$ and 3.6 to $2.9 \mathrm{~nm}$, respectively. The pore size increased from $2.8 \mathrm{~nm}$ to $3 \mathrm{~nm}$ upon increasing the calcination temperature from 500 to $600^{\circ} \mathrm{C}$. Unsupported membranes were heat treated in the 200 to $1200{ }^{\circ} \mathrm{C}$ range for the characterization of the phase structure. Pinhole and crack free alumina membranes about $3 \mu \mathrm{m}$ (2-layer) in thickness was observed from the SEM pictures with insignificant infiltration. The $\mathrm{CO}_{2}$ permeability through the double layer $\gamma-\mathrm{Al}_{2} \mathrm{O}_{3}$ membrane calcined at $600{ }^{\circ} \mathrm{C}$ was $2.25 * 10^{-7} \mathrm{~mol} / \mathrm{m}^{2} . \mathrm{s} . \mathrm{Pa}$, and had a slight pressure dependence indicating Knudsen Diffusion and Laminar Flow being the effective transport mechanisms. Upon the calcination of a similar 2-layer alumina membrane at $500^{\circ} \mathrm{C}$, the $\mathrm{CO}_{2}$ permeability decreased to $1.51 * 10^{-8} \mathrm{~mol} / \mathrm{m}^{2}$.s.Pa. without pressure dependence.
\end{abstract}

\section{Introduction}

The superior thermal/chemical/mechanical stability and the ability of ceramic membranes in affecting the transport rates of chemical species through their processing controllable pore structures makes them very attractive for many separation problems. The preparation of metal oxide ceramic membranes is generally conducted by sol-gel techniques. This technique attracts most attention due to its excellent processibility and its potential to close control pore size and pore structure(1). Usually, the metal oxide is initiated into the process as a metal alkoxide solution. The metal is hydrolysed to metal hydroxide monomers, clusters or particles. The insoluble metal oxide particles are the peptised by the addition of acid or base to obtain a sol.Upon solvent removal as semi-solid material is called gel. Further evaporation and then heat treatment of the gel results in a durable rigid material which can either be formed as an unsupported membrane or as a supported membrane coated onto a porous substrate(2). Three keys to membrane production are (i) avoidance of cracks, pinholes and other defects that reduce the selectivity, (ii) precise pore size control and (iii) maximisation of porosity and minimisation of the membrane thickness to maximise flux (1).

In order to obtain an effective gas separation membrane, two demands should be important. First, the membrane should be highly permeable and the second the selectivity should be high (3). The transport of pure gases through $\gamma-\mathrm{Al}_{2} \mathrm{O}_{3}$ membranes occurs by three mechanisms: Knudsen diffusion, laminar flow and surface diffusion. Knudsen diffusion occurs when the mean free path of the gas molecules is larger than the mean pore radius of the membrane, but there is no or only a weak interaction with the membrane materials. Gases can be separated by Knudsen diffusion due to differences in their molecular weights. Since the pore size of the $\gamma-\mathrm{Al}_{2} \mathrm{O}_{3}$ membranes are very small, laminar flow is considered to be negligible in the case of defect-free membrane (4).

In this study, the relationships between the parameters that used in $\gamma-\mathrm{Al}_{2} \mathrm{O}_{3}$ membrane preparation and the gas transport properties were studied. 


\section{Experimental}

Boehmite sols $\left(\mathrm{H}^{+} / \mathrm{Al}^{3+}=0.25, \mathrm{H}_{2} \mathrm{O} / \mathrm{Al}^{3+}=100\right)$ were prepared by the hydrolysis of aluminium isopropoxide (Aldrich,98\%), at a temperature $80{ }^{\circ} \mathrm{C}$ for 3 hours. The hydroxide precipitate was peptised with appropriate amounts of nitric acid to form a stable colloidal solution.

Zirconia support disks were prepared from partially stabilised zirconia powder (TOSOH,TZ-3Y, $\mathrm{d}_{50}=0.18 \mu \mathrm{m}$ ) using slip casting techniques. Supports, $4.5 \mathrm{~cm}$ in diameter and $2 \mathrm{~mm}$ in thickness were sintered at $1150{ }^{\circ} \mathrm{C}$ for $3 \mathrm{~h}$, with a heating rate $10{ }^{\circ} \mathrm{C} / \mathrm{min}$. These substrates were then dipped into a diluted boehmite sol for $10 \mathrm{~s}$. then, the membranes were dried at room temperature for 15 minutes. Unsupported and supported $\gamma-\mathrm{Al}_{2} \mathrm{O}_{3}$ membranes were prepared in the 500 to $600{ }^{\circ} \mathrm{C}$ range (3hours hold, $4{ }^{\circ} \mathrm{C} / \mathrm{min}$ heating rate). And characterize by $\mathrm{N}_{2}$ adsorption/desorption (MicromeriticsASAP 2010), XRD (Phillips X'pert Pro), and SEM (Phillips XL30S SFEG). The sol particle size distributions were determined by ZetaSizer 3000 HAS.

Single gas permeation was carried out for pure gases $\mathrm{O}_{2}, \mathrm{~N}_{2}$ and $\mathrm{CO}_{2}$ by using pressure controlled dead-end mode membrane test system at room temperature. Gas at a constant pressure of 2-3 atm was introduced in the feed side. Pressure increase in the downstream side was measured. The measured membrane area was $12.5 \mathrm{~cm}^{2}$.

\section{Results and Discussion}

Clear sols were obtained with $\mathrm{HNO}_{3} /$ Alkoxide mole ratio in the 0.07-0.4 and the minimum particle size was obtained at $0.25 \mathrm{H}^{+} / \mathrm{Al}^{3+}$ ratio. Particle size distribution in the boehmite sol $(0.2 \mathrm{~mol} \mathrm{Al} / \mathrm{lt})$ is shown in Figure1. The sol had a sharp peak at around $13 \mathrm{~nm}$. The XRD pattern of the dried gel revealed the presence of boehmite as shown in Figure 2. The XRD size was obtained from Scherrers equation at about $5 \mathrm{~nm}$.

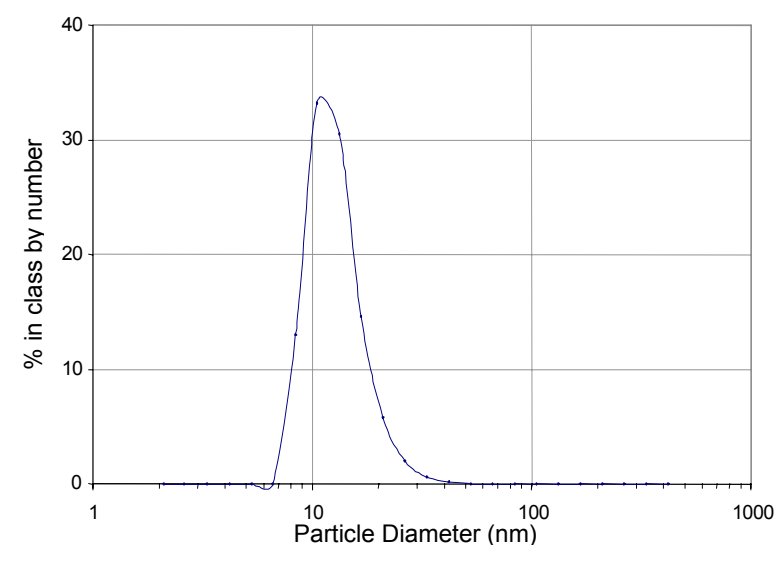

Figure 2. Number based PSD of A08.

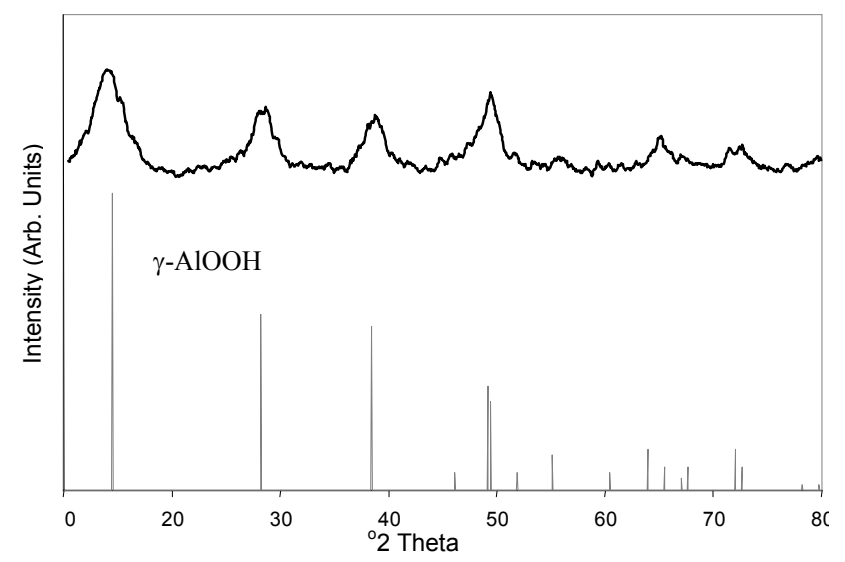

Figure 3. XRD pattern of $200^{\circ} \mathrm{C}$ dried film.

Unsupported membranes were heat treated in the 200 to $1200{ }^{\circ} \mathrm{C}$ range for the characterization of the phase structure. Boehmite was the dominant phase below $500{ }^{\circ} \mathrm{C}$, gamma being the dominant phase up to $900{ }^{\circ} \mathrm{C}$ and pure $\alpha-\mathrm{Al}_{2} \mathrm{O}_{3}$ phase was obtained upon heat treatment at $1200^{\circ} \mathrm{C}$.

The increase in the acid content of the sol caused almost proportional decreases in both sol particle size and $600{ }^{\circ} \mathrm{C}$ calcined membrane pore diameter as shown in Figure 3. This obviously indicates the fact that packing of smaller particles results in finer pore structures. The significant implication of this would be the ability of designing of the microstructure of the membrane. 


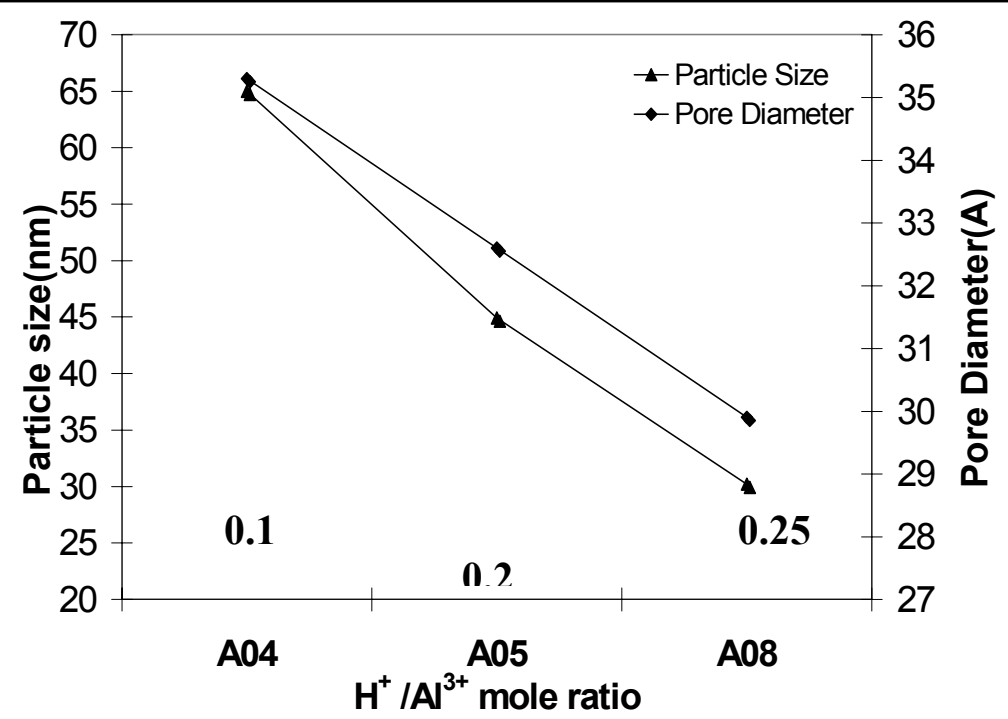

Figure 3. Effect of acid content on the mean sol particle size and the mean pore size membrane.

One of the advantages of the sol-gel processing for preparing membranes is the increase of the pore diameters when the firing temperature is increased, so this fact permit the choice of calcination temperature for applications. The unsupported membrane had a BET surface area of $305 \mathrm{~m}^{2} / \mathrm{g}$ and pore size of $2.8 \mathrm{~nm}$ when calcined at $500{ }^{\circ} \mathrm{C}$. The pore size increased from $2.8 \mathrm{~nm}$ to $3 \mathrm{~nm}$ upon increasing the calcination temperature from 500 to $600{ }^{\circ} \mathrm{C}$. The nitrogen desorption isotherm based $\mathrm{BJH}$ pore size distribution of $500{ }^{\circ} \mathrm{C}$ calcined membrane is presented in Figure 4. Figure 5 shows the microstructure of the fracture surface of the two layer alumina membrane which was treated at $600{ }^{\circ} \mathrm{C}$ and $500{ }^{\circ} \mathrm{C}$. It was found that, $\gamma-\mathrm{Al}_{2} \mathrm{O}_{3}$ membranes thickness after 2 dipping procedure without significant penetration was about $3 \mu \mathrm{m}$.

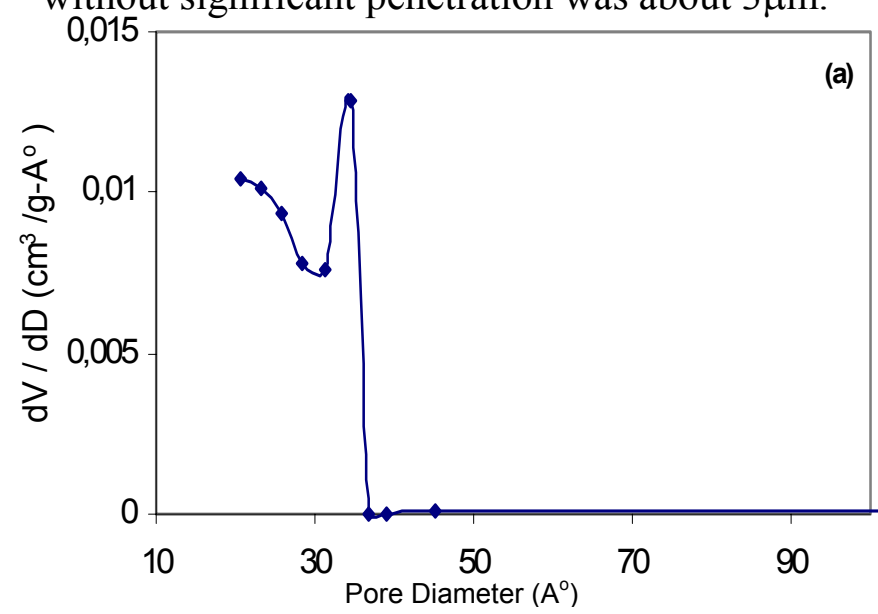

Figure4. BJH pore size distribution plots for $500{ }^{\circ} \mathrm{C}$ Figure 5.SEM micrograph of fracture surface calcined membrane.

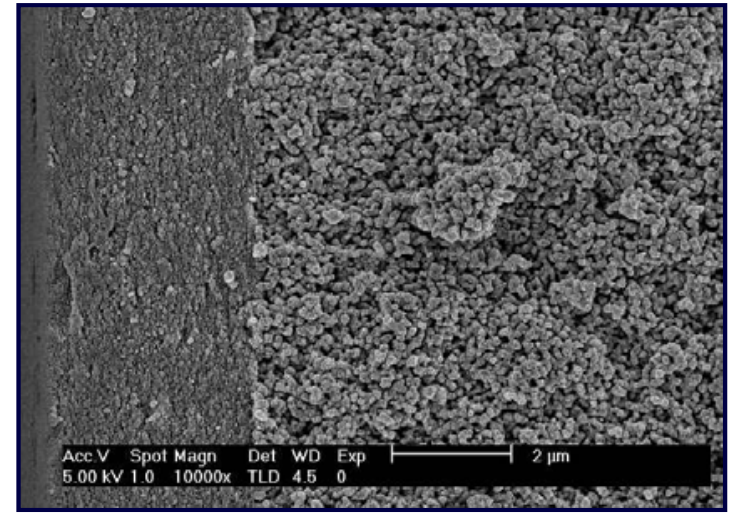

of 2-layer alumina membrane: $\times 100000$

The effect of calcination temperature on $\mathrm{N}_{2}$ permeabilitiy through 1-layer membranes as a function of pressure is shown in Figure 6. The presence of a combined Knudsen and Laminar flow transport mechanism is indicated by the slight pressure dependence.Although $500{ }^{\circ} \mathrm{C}$ treated alumina membrane had a sharp pore size distribution with a mean pore diameter of $2.7 \mathrm{~nm}, 600{ }^{\circ} \mathrm{C}$ treated membrane had a relatively broad pore size distribution with a mean pore diameter of $2.9 \mathrm{~nm}$. The change in the pore size caused increases in the gas permeability through the membrane. Also as shown in Figure 7, the increase in heat treatment temperature caused reduced permselectivities of these gases. 


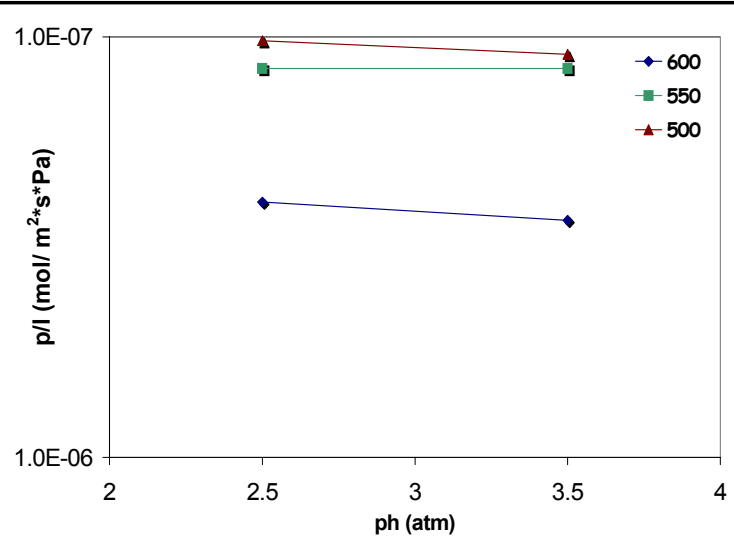

Figure 6. Calcination temperature effect on $\mathrm{N}_{2}$ permeation for 1-layer membrane

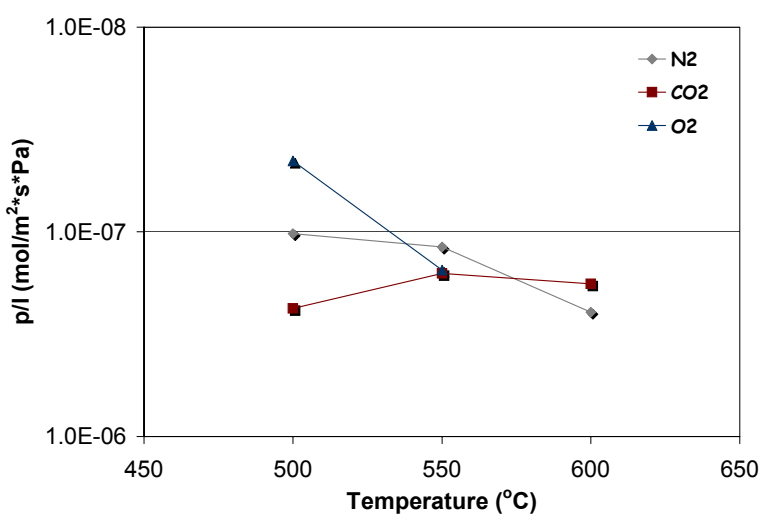

Figure 7. Separation efficiency of membranes at different heat treatment temperature

The effects of repeated dipping-drying-firing on the permeabilities of $\mathrm{N}_{2}$ and $\mathrm{CO}_{2}$ through the alumina membrane is given in Figure 8 (a) and (b). The permeabilities decreased with the number of coating cycles due to the increase of the thickness of the alumina layer on the substrate. After the first dipping, as can be seen in these figures, permeation level of two gases were constant at both pressures indicating that permeation was pressure independent. This implies that the dominant transport mechanism for the membranes is Knudsen diffusion as could be expected with a pore size in the $2.5-3 \mathrm{~nm}$ range.

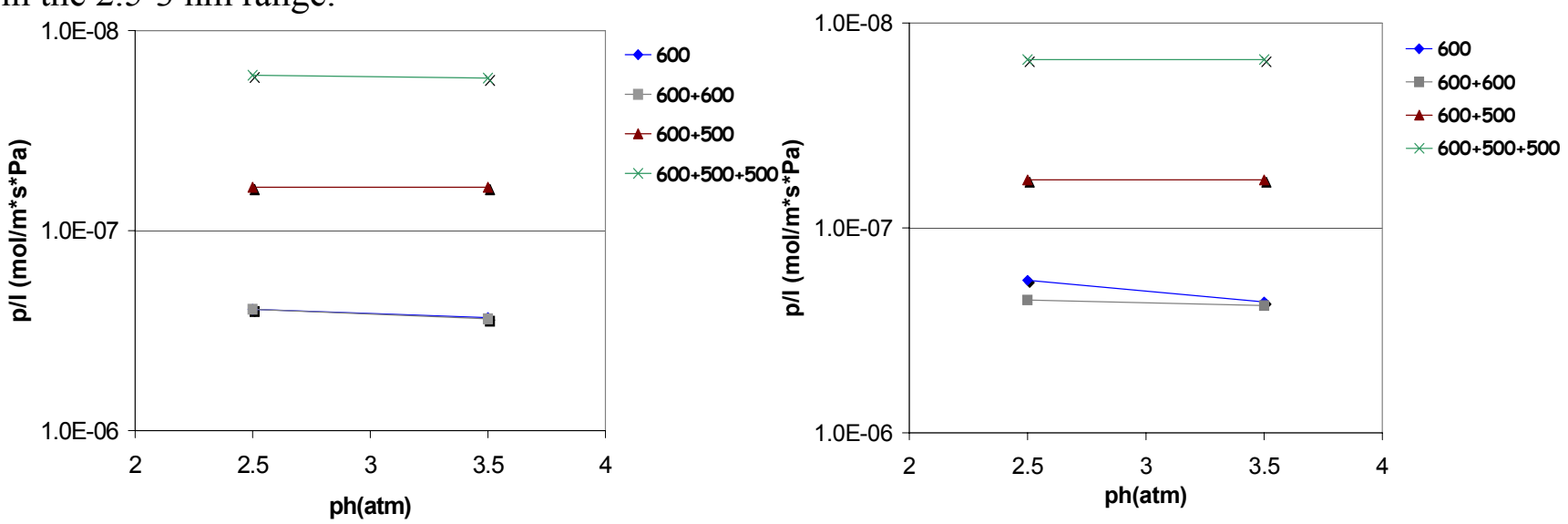

Figure 8. (a) $\mathrm{N}_{2}$ permeance, (b) $\mathrm{CO}_{2}$ permeance variation with number of layers.

\section{Conclusions}

Thin membranes of $\gamma-\mathrm{Al}_{2} \mathrm{O}_{3}$ with a narrow pore size distribution and a pore size of $2.8 \mathrm{~nm}$ were produced by sol-gel processing. The pore structure can be tailor made by varying heat treatment temperature and acid concentration of the sol. Pinholes and cracks were eliminated by repeated dipping-drying-firing steps. Permeance of gases investigated in this work through $\gamma-\mathrm{Al}_{2} \mathrm{O}_{3}$ membranes were independent of the mean pressure across the membrane except for the $600{ }^{\circ} \mathrm{C}$ treated one layer alumina membrane. Knudsen diffusion is dominant transport mechanism in the 2layer alumina membranes.

\section{References}

[1] Brinker C.J., Sehgal R., Hietala S.L., Deshpande R., Smith D.M., Loy D. and Ashley C.S., Journal of Membrane Science, 94, pp:85-102, (1994).

[2] Ward D. A., Ko E.I., Ind. Eng. Chem. Res. ,34, pp:421-433 (1995).

[3] Morooka, S. and Kusakabe K., MRS Bulletin 24(3), pp.25-28 (1999).

[4] Bhave, R. R.: Inorganic Membranes, Synthesis, Characteristics and Applications, (Van Nostrant Reinhold, USA 1991). 


\section{Euro Ceramics VIII}

10.4028/www.scientific.net/KEM.264-268

Investigation of the Permeability of Pure Gases in Sol-Gel Derived $\mathrm{Al}_{2} \mathbf{O}_{3}$ Membrane 10.4028/www.scientific.net/KEM.264-268.399

\section{DOI References}

[2] Ward D. A., Ko E.I., Ind. Eng. Chem. Res. ,34, pp:421-433 (1995).

10.1021/ie00041a001 